\title{
RETOMANDO A IDENTIDADE TRADICIONAL
}

\author{
Cleberson Iakymytywygi Tapirapé
}

\section{RESUMO}

O meu objetivo do projeto de estágio é amplo, pois há o cultivo de conhecimento. Descobrir valores da cultura por meio da pesquisa e buscar das pessoas mais velhas que conhecem a história e que guardam em si muito conhecimento. Por meio da minha pesquisa consegui deixar para os estudantes da minha escola conhecimentos que voltam a circular na comunidade. Isso porque os livros didáticos vindos de fora não conseguem esse efeito cultural. Essa atitude pedagógica é relevante para escola e, principalmente, para a alfabetização.

PALAVRAS-CHAVE: Conhecimentos tradicionais. Identidade tradicional. Alfabetização.

\begin{abstract}
My goal of the internship project is wide, as there is the cultivation of knowledge. To discover values of culture through the search and search of the older people who know the history and who keep in themselves much knowledge. Through my research, I have been able to let the students of my school know that they are moving back into the community. This is because textbooks from outside do not achieve this cultural effect. This pedagogical attitude is relevant for school and, especially, for literacy.
\end{abstract}

KEYWORDS: Tradicional Knowledges. Tradicional Identity. Literacy.

1 Licenciado no Curso de "Educação Intercultural" (Ciências da Cultura) pela Universidade Federal de Goiás e Especialista em "Educação Intercultural e Transdisciplinar: Gestão Pedagógica", pela mesma Universidade. Professor da Educação Básica. Escola Estadual Indígena Hawalòra. Pesquisador da Ação “Saberes Indígenas na Escola”, Rede UFG/UFT/UFMA. Aldeia Hawalòra, MT, Brasil. E-mail: iakymytywygi@gmail.com. 


\section{Aprendizagem dos Alunos}

A segunda aprendizagem dos alunos é a educação escolar, porque a primeira da vida é recebida dos pais. $\mathrm{O}$ conhecimento aprendido pelas crianças na casa não é ensinado como na escola, porque na escola os professores ensinam os alunos com várias explicações do letramento e ilustração. Já, em casa, eles aprendem praticando a realidade, falando sobre ela, nas brincadeiras, entre outros. As meninas aprendem a cozinhar, a fazer artesanato, enquanto os meninos aprendem a caçar e a pescar. Assim, eles vão se preparando para a fase adulta.

\section{Aprendendo na escola}

Foto 1 - Aprendendo na Escola Hawalòra.

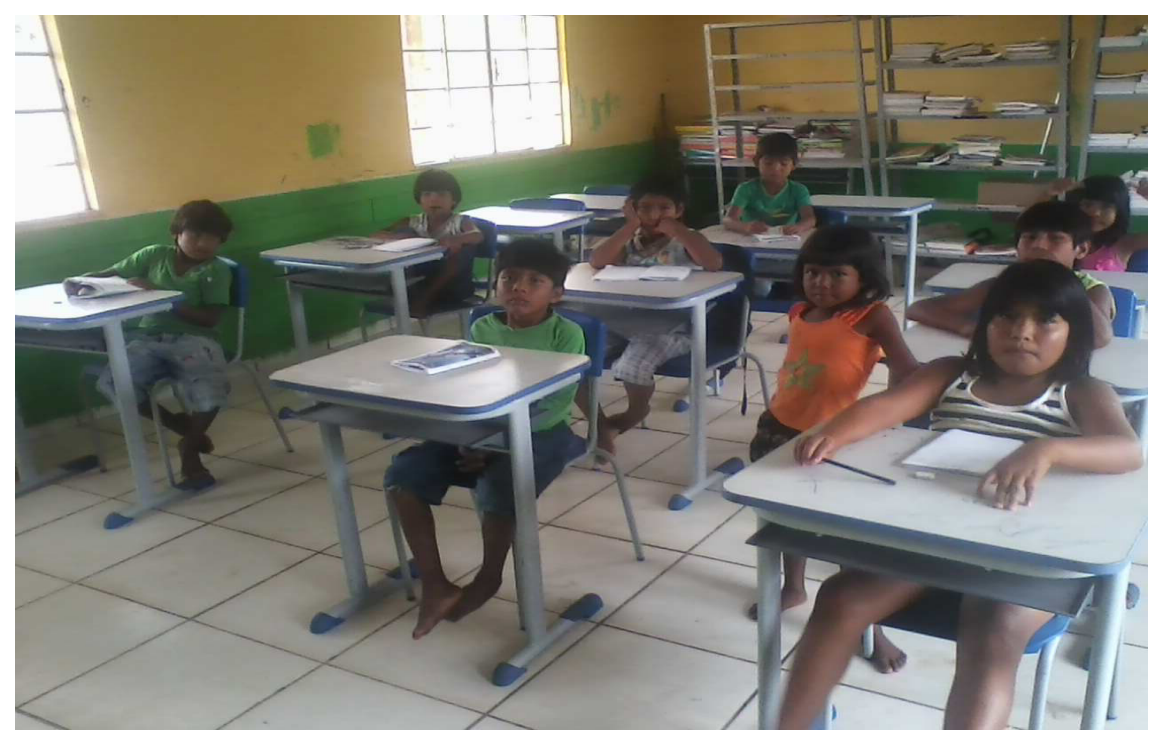

Fonte: Cleberson Iakymytywygi Tapirapé.

\section{Aprendendo na Comunidade}

Durante cinco anos de estudo na educação intercultural, a minha experiência como pesquisador e como acadêmico foi muito 
importante para a sala de aula, porque me ajudou bastante no desenvolvimento de prática de sala de aula: descobrir a cada dia, uma coisa nova.

Antes, seguindo a imagem dos não índios, não pensávamos que o peixe poderia acabar e que alguns peixes já se encontram quase em extinção, como Pirarucu, Tucunaré e a Tartaruga. Para nós, indígenas, esses peixes têm muito valor para a realização de nossos rituais e para as famílias terem uma vida saudável.

Foto 2 - Pescando com arco e flecha.

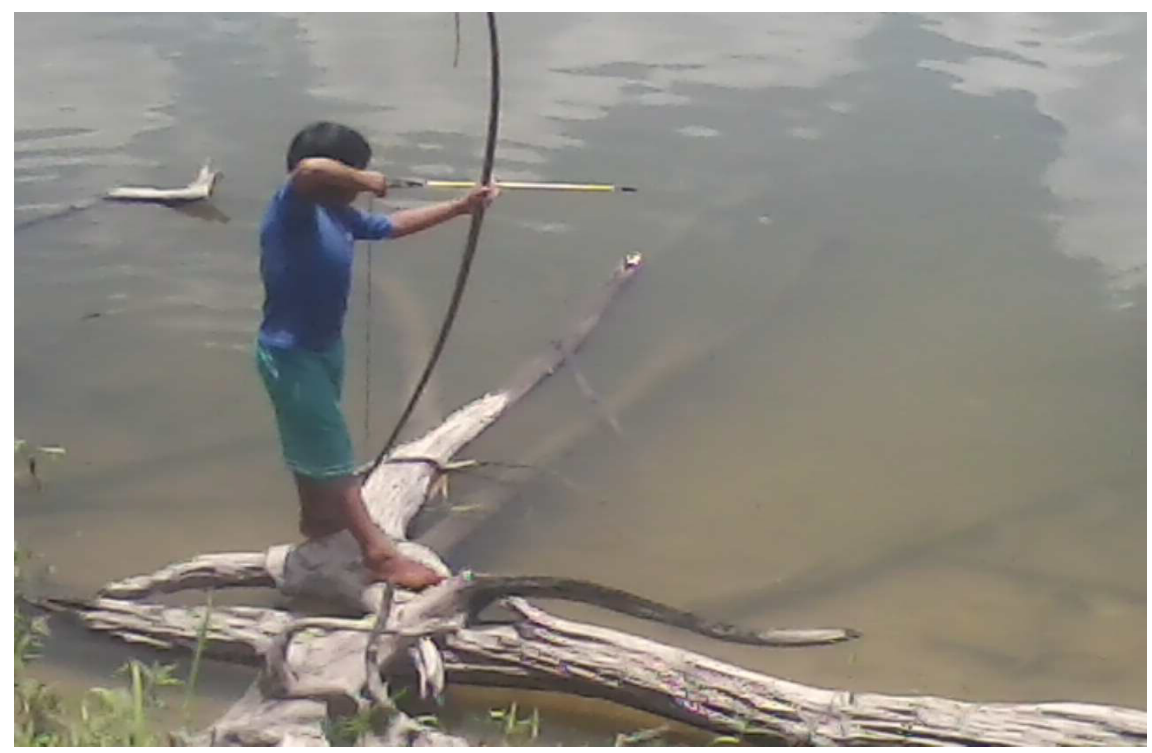

Fonte: Cleberson Iakymytywygi Tapirapé.

Em sala de aula, a meta era procurar mais informações para debater com nossos alunos. Buscamos conhecimento na comunidade para levarmos para a sala de aula. Os alunos produziam textos referentes às pesquisas realizadas. 
Foto 3 - Atividades escritas produzidas pelos alunos.
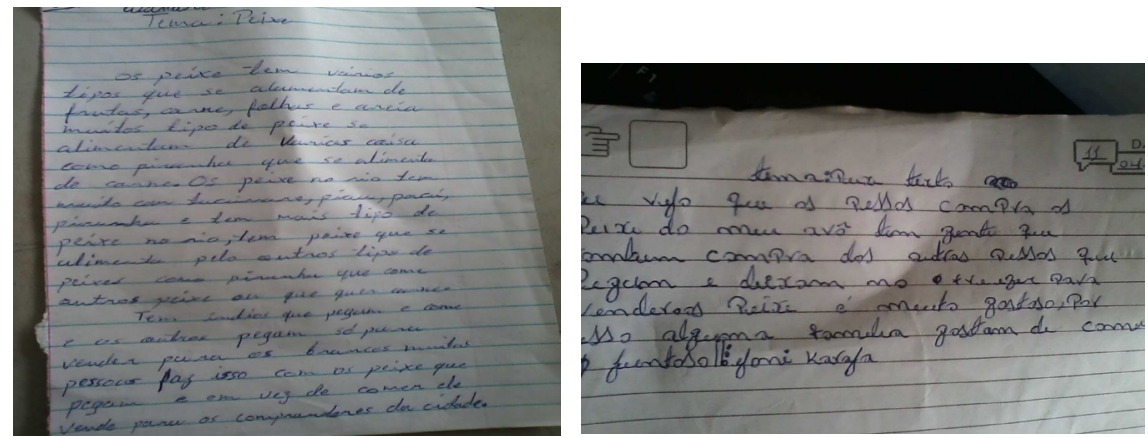

Fonte: Cleberson Iakymytywygi Tapirapé.

Foto 4 - Desenhos produzidos pelos alunos.
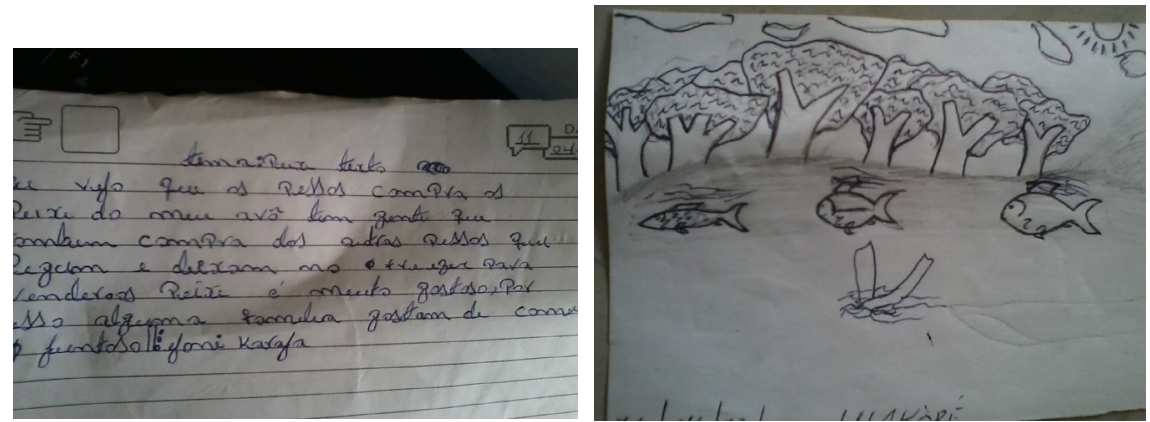

Fonte: Cleberson Iakymytywygi Tapirapé.

E os alunos, no início, tiveram dificuldades de trabalhar com a pesquisa, mas isso não impediu que levasse adiante meu trabalho, fiz várias exposições para facilitar e reforçar o conhecimento dos alunos que já é praticado na convivência na comunidade. Esse conhecimento é lembrado na hora de ser produzido no texto. Os alunos foram excelentes e dedicados em cada momento na realização dos trabalhos.

No planejamento de minhas aulas, levei em conta a concepção de educação intercultural e transdisciplinar. Essa concepção ajuda a buscar o que está sendo esquecido pelos mais jovens. No meu estágio, aprendi coisas que eu não sabia da minha cultura e isso me fortaleceu para fazer um bom trabalho com os jovens, movimentando as gerações. Por exemplo, tempo atrás, as festas, caçadas e pescaria 
não aconteciam envolvendo a todos, era só individual. Hoje, o pessoal está voltando a ser como antigamente, ou seja, tudo em conjunto na pescaria e na caçada.

Recentemente, o pessoal foi matar tartaruga para mostrar para o jovem. Isso não acontecia mais. Não foi fácil o curso de educação intercultural, mas de tanto eu procurar as respostas do meu objetivo, achei o caminho do meu trabalho, e descobri muita coisa que as pessoas deixaram de usar. Sempre quando realizava o meu relato do trabalho com um ancião, no meio da conversa dele, ele falava da geração nova, que estão esquecendo muitas coisas, canto, dança, artesanato, confeccionar enfeite de uso pessoal e até a própria língua está se misturando com o português, quando estão se expressando entre eles mesmos.

Desde o começo, esse curso teve grande valor no fortalecimento das tradições da cultura por meio da pesquisa e facilitando o ensino na sala de aula. Meu trabalho foi realizado em duas aldeias: Tapi'itãwa e Myryxitãwa, junto com o senhor Iapire'i Tapirapé, senhora Mareapawygi Tapirapé, Awaetekato’i Tapirapé e demais que foram entrevistados. Essas pessoas colaboraram bastante na minha pesquisa por estarem sempre dispostos no momento de contribuir contando histórias, mitos, entre outros.

Além de todas as dificuldades, esse curso me fez renascer e acordar vivendo novamente na minha comunidade, aprendendo por meio das pesquisas e entrevistas, praticando hoje por todas as pessoas, vendo que fomos transformados de novo. Através desse curso, a nossa comunidade tem a visão que a própria sociedade indígena não tinha valorizado a sua cultura e hoje já teve avanço de realizar, mostrando para as crianças e vendo tão bonito as crianças imitando também, aprendendo desde pequenas.

Então, isso para a comunidade foi elogiado: que os acadêmicos têm resgatado várias coisas que existem na cultura. Para minha experiência própria, hoje me sinto ampliando a visão sobre o meio em que vivemos, tenho uma visão mais rica do nosso conhecimento. Tudo isso aprendi e conheci estudando no curso de Educação Intercultural da UFG. 
Foto 5 - Danças de rituais Tapirapé.

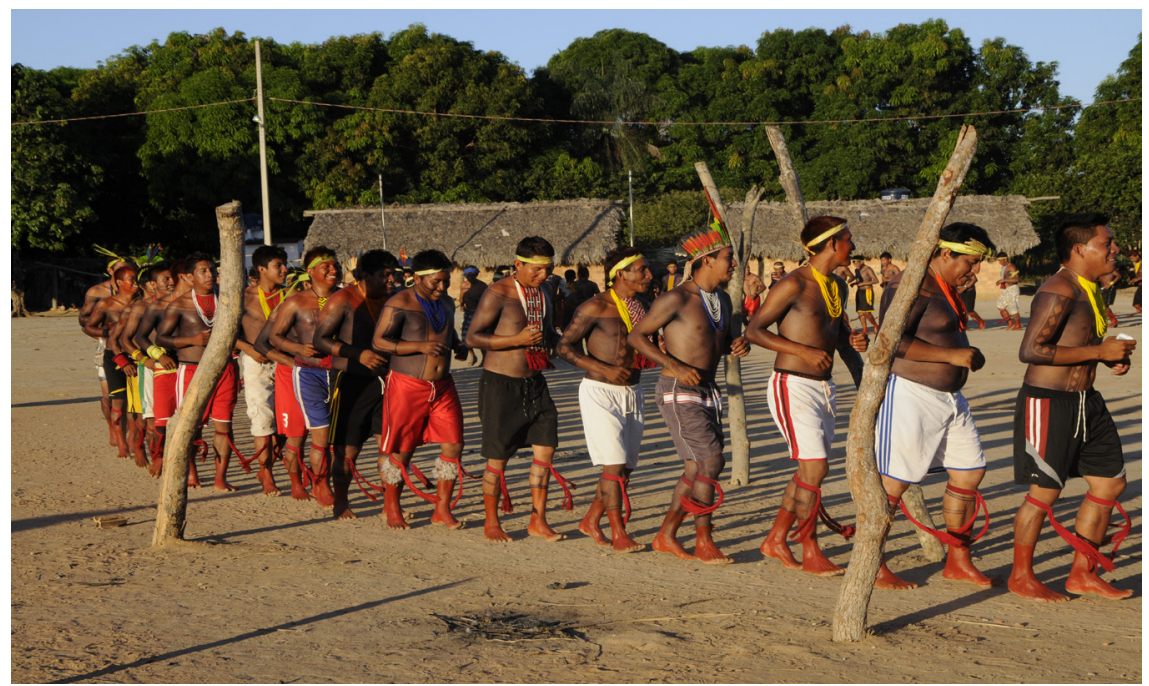

Fonte: Cleberson Iakymytywygi Tapirapé.

Foto 6 - Crianças com vestimenta cultural de acordo com a sua idade.

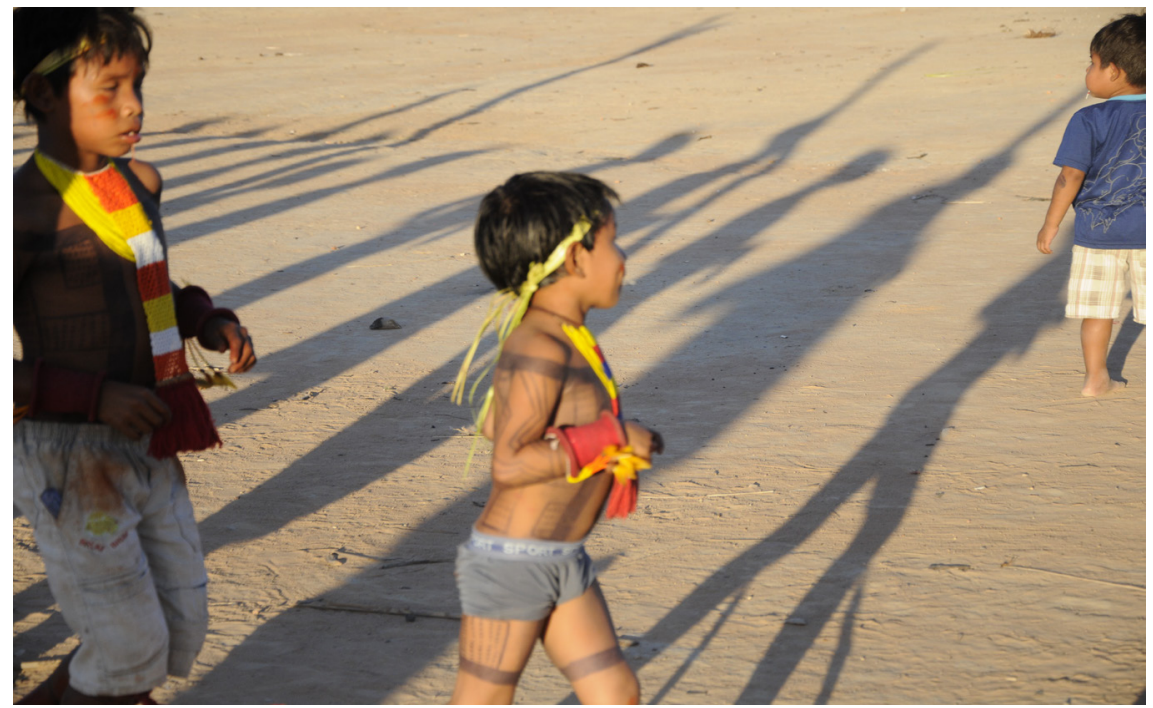

Fonte: Cleberson Iakymytywygi Tapirapé. 


\section{Agradecimento}

Agradeço, primeiramente, ao Senhor Deus, por levar minha vida mesmo diante de todas as consequências por que passei, ausente da minha família. Em segundo, a todos que me ajudaram, me incentivaram para seguir em frente com meus estudos, todas as minhas famílias, às pessoas que colaboraram para a realização do meu trabalho e a todos professores do meu primeiro ensino na escola e hoje são as pessoas mais importantes que estiveram sempre atenciosas, não só comigo, mas sim com todos os colegas de estudo, professores da Educação Intercultural, no incentivo do trabalho, colaborando para que os projetos cheguem em seu objetivo, com avanço e, principalmente, à Maria do Socorro Pimentel da Silva, por esse projeto tão importante, pois os povos indígenas retomam suas tradições na comunidade por meio do estudo.

\section{Referências}

PIMENTEL DA SILVA, M. do. S. A pedagogia da contextualização intracultural e intercultural. Texto inédito, 2012.

. Pedagogia da retomada: decolonização de saberes. Revista Articulando Saberes. Vol. 1. , n 2, pp. 203 a 215.

IAKYMYTYWYG, Cleberson Tapirapé. Relatório da Especialização em Educação Intercultural e Transdisciplinar: Gestão Pedagógica. Goiânia: UFG/Núcleo Takinahaky de Formação Superior Indígena, 2016.

Recebido para publicação em abril de 2018. Aceito para publicação em junho de 2018. 